\title{
Intimate partner violence and mental health problems among Sami and non-Sami in Norway - the SAMINOR 2 Questionnaire Survey.
}

\section{Astrid M.A Eriksen ( $\nabla$ astrid.m.eriksen@uit.no)}

UiT Arctic University of Norway: UiT Norges arktiske universitet

\section{Marita Melhus}

UiT Arctic University of Norway: UiT Norges arktiske universitet

\section{Bjarne Koster Jacobsen}

UiT Arctic University of Norway: UiT Norges arktiske universitet

\section{Berit Schei}

Norwegian University of Science and Technology Faculty of Engineering Science and Technology: Norges teknisk-naturvitenskapelige universitet Fakultet for ingeniorvitenskap

\section{Ann-Ragnhild Broderstad}

UiT Arctic University of Norway: UiT Norges arktiske universitet

\section{Research article}

Keywords: intimate partner violence, childhood violence, Sami, mental health, post-traumatic stress

Posted Date: October 9th, 2020

DOl: https://doi.org/10.21203/rs.3.rs-87493/v1

License: (c) (i) This work is licensed under a Creative Commons Attribution 4.0 International License. Read Full License 


\section{Abstract}

Background: Mental health problems is an important contributor to the global burden of disease. Exposure to intimate partner violence (IPV) and violence in childhood (CV) is associated with mental health problems. These issues are scarcely studied among the Sami. This study estimates the prevalence of IPV and its association to mental health problems among Sami and non-Sami, and whether the effect of IPV on mental health was altered by exposure to CV. To our knowledge, this is the first populationbased study estimating IPV and its association to mental health problems among Sami and non-Sami in Norway.

Methods: This study was based on the cross-sectional SAMINOR 2 Questionnaire Survey, a part of the Population-based Study on Health and Living Conditions in Regions with Sami and Norwegian Populations - the SAMINOR Study. Pearson's chi-square tests and two-sample t-tests were used for testing differences between groups and multiple linear regression analysis was applied to explore the association between IPV/CV and mental health problems (continuous scores of psychological distress and symptoms of post-traumatic stress).

Results: A total of $12.8 \%$ of women and $2.0 \%$ of men reported to have experienced any IPV (emotional, physical, and/or sexual). A significantly higher proportion of Sami women reported exposure to emotional (12.4\% vs. $9.5 \%, p=.003)$, physical (11.6\% vs. $6.9 \%, p<.001)$, and any IPV (17.2\% vs. $11.8 \%, p<.001)$ compared to non-Sami women. There were no ethnic differences in sexual IPV among women $(2.1 \%$ vs. $1.8 \%, p=.5)$. The study demonstrated that being exposed to emotional, physical, or sexual IPV is associated with mental health problems. The most severe mental health problems were observed among those who reported both IPV and CV. There were no ethnic differences in the association between the different types of IPV and mental health problems, and we observed overall similar results among men and women.

Conclusions: The most severe mental health problems were observed for those who were exposed to both IPV and CV. It is therefore important for victims of IPV to address experiences of violence in childhood. The effect that IPV and CV have on mental health problems seems to be same, regardless of ethnicity and gender.

\section{Introduction}

Intimate partner violence (IPV) is a serious public health issue that adversely affects both mental and physical health (1). The magnitude and pattern of IPV vary across countries, regions, genders, and ages (2-4). Even though some studies have found that men report being victims of violence just as often as women, women are far more likely to be injured during assaults by intimate partners than are men, and women suffer both sexual and more severe forms of violence. When women report being the perpetrators of violence, it is more likely to be in self-defense (1). The World Health organization (WHO) has identified IPV as the most common form of violence against women (5). It is estimated that approximately $30 \%$ of 
ever-partnered women have experienced physical and/or sexual violence at the hands of an intimate partner (1). Broad ranges of health outcomes, including mental health problems, have been associated with IPV among women (6-8). An early meta-analysis by Golding reported that suicidal ideation, substance abuse, post-traumatic stress disorder (PTSD), and depression were three to five times more frequent among female victims of IPV when compared with non-victimized women (9). Mental health problems are also strongly associated with a history of child abuse $(10,11)$. Furthermore, abused children are at high risk of further victimization as adolescents or adults $(12,13)$. Given that many of those who experience childhood violence (CV) are also exposed to IPV, it is important to investigate the impact of experiencing both $(14,15)$.

In Norway, a country with a comprehensive welfare system and high gender equality, the first populationbased study on IPV among women and men was conducted in 2003/2004 and showed an extensive use of physical power and violence in intimate relationships (16). More than $25 \%$ of women and $20 \%$ of men reported that their former and/or current partner had used physical power against them (16). Potential life-threatening violence (attempted strangulation, use of weapons, beating of the head against an object or wall) was reported by $9 \%$ of women and $2 \%$ of men. Further, $9 \%$ of women reported that a partner had tried to force them to have sex, and $27 \%$ reported any lifetime IPV (mild, moderate, and/or severe IPV among ever partnered-women) (17). A national population-based survey conducted in 2013 showed that $9 \%$ of women reported severe IPV compared to $2 \%$ of men, and $15 \%$ of respondents reported "not severe" physical IPV/IPV from a current or previous partner, with no significant gender differences. However, women reported a higher number of violent episodes than men did (18). Among those exposed to IPV, $40 \%$ of women and $28 \%$ of men reported to have been exposed to more than five episodes of not severe IPV. Forty-one percent of women exposed to rape reported that the perpetrator was a partner/former partner; the corresponding figure among men was $13 \%$. None of these studies measured the exposure to emotional/psychological IPV (18).

Globally, studies on IPV among indigenous populations are sparse. A systematic review from 2017 identified 13 studies that focused on indigenous populations, IPV, and mental health (19). Most of these studies were conducted in North America (nine studies), followed by Australia, New Zealand, the Pacific Islands, and Asia (one study each). Most studies reported high rates of IPV, although methodological difficulties were identified. The strongest predictor of poor mental health in this review was physical IPV, and the most commonly reported mental health outcomes were depression and PTSD (19). Studies have shown that indigenous women from Canada report the highest rates of IPV in the nation and are two to three times more likely to report IPV from a current or former partner than non-indigenous women (20, 21).

The Sami are an ethnic minority living in Norway, Sweden, Finland, and the Kola Peninsula of the Russian Federation. Most of the Sami live in Norway, where they are recognized as the indigenous people. The Sami have been subjected to harsh assimilation policies for over 100 years. Health disparities between indigenous peoples and their majority populations have often been linked to colonization, forced assimilation, violence, and discrimination $(22,23)$. A number of media articles have focused on sexual 
violence in Sami communities, but little research on IPV and the association between IPV and mental health has been done among the Sami $(24,25)$. A previous study revealed that Sami participants reported more violence in both childhood and adulthood as compared to non-Sami participants (26). However, that study did not focus on the relationship between the victim and the abuser. Another study found an association between childhood abuse and mental health symptoms in adulthood (27). To our knowledge, there has not been any population-based study on IPV alone or IPV in combination with CV in Sami and non-Sami populations.

\section{Aims of the study}

The aims of the study were 1) to estimate the prevalence of IPV among Sami and non-Sami women and men; 2 ) to investigate the association between IPV and mental health problems (psychological distress and symptoms of post-traumatic stress (PTS)), and explore whether these associations differed between Sami and non-Sami; and 3) to determine whether the effect of IPV on mental health problems was altered by exposure to $\mathrm{CV}$.

\section{Materials And Methods}

This study was based on the cross-sectional SAMINOR 2 Questionnaire Survey, part of the second wave of the Population-based Study on Health and Living Conditions in Regions with Sami and Norwegian Populations - the SAMINOR Study (28). The survey was conducted in 2012 by the Centre for Sami Health Research, UiT The Arctic University of Norway. The questionnaire, including an English translation, is available at www.saminor.no.

\section{Sample}

The study population included all inhabitants aged 18-69 years living in 25 selected multi-ethnic municipalities (mixed Sami and non-Sami populations) in Northern and Central Norway (in six of the municipalities only selected districts were included). Out of 43,245 invitees, 11,600 participated, yielding a participation rate of $27 \%$. In the present study, 96 respondents were excluded due to missing information on ethnicity, 121 due to missing information concerning violence, 567 due to missing information on three or more items on the 10-item version of the Hopkins Symptoms Checklist (HSCL-10), and 26 due to missing information on all three questions regarding symptoms of PTS. Thus the total analytic sample consisted of 10,790 participants: 6003 (55.6\%) women and 4787 (44.4\%) men.

\section{Ethnicity}

Ethnicity was categorized as Sami or non-Sami based on information collected from the questionnaire. To be categorized as Sami, two criteria had to be met: the subjective criterion of self-perceived Sami ethnicity (whether the respondents consider themselves to be Sami) and the more objective criterion of Sami linguistic affiliation (if at least one grandparent, parent, or the participants themselves use(d) Sami as the home language). These criteria resemble those used by the Norwegian Sami Parliament to register voters. All other participants were categorized as non-Sami. Among the 10,790 participants, the use of 
this classification resulted in 2,116 Sami (19.6\%) and 8,674 non-Sami (80.4\%). However, as there is no consensus on how to define Sami ethnicity, and different classifications have been in operation $(29,30)$, sensitivity analyses were performed using an alternative ethnic categorization. In this alternative, the subjective criterion was changed to a positive answer to at least one of the following questions: "I consider myself Sami" and "My ethnic background is Sami". The same objective criterion of Sami linguistic affiliation was also applied, and participants who met both of these criteria were classified as Sami and all others as non-Sami. This alternative ethnic categorization expanded the Sami group to 2603 (1141 [23.8\%] Sami men and 1462 [24.4\%] Sami women).

\section{Intimate partner violence and childhood violence}

Experience with emotional, physical, and sexual violence, respectively, was measured using questions from the Norvold Abuse Questionnaire (NorAQ), with one question for each type of violence. In their responses, participants could indicate whether the violence occurred in adulthood and/or in childhood, and indicate the perpetrator with the following response options: "Stranger", "Spouse" (married or cohabiting partner), "Family/relative”, and/or "Other acquaintance”. Multiple answers were allowed.

Participants who answered "Yes, as an adult" and/or "Yes, past 12 months" to the question "Has anyone ever systematically and over a long period tried to subdue, degrade, or humiliate you?", and in addition ticked "Spouse/partner" as the perpetrator, were classified as exposed to emotional IPV. The remaining respondents were classified as non-exposed. Participants who answered "Yes, as an adult" and/or "Yes, past 12 months" to the question "Have you experienced physical attacks/abuse?", and in addition ticked "Spouse/partner" as the perpetrator, were classified as exposed to physical IPV, and the remaining respondents were classified as non-exposed. Participants who answered "Yes, as an adult" and/or "Yes, past 12 months" to the question "Have you been sexually abused?", and in addition ticked "Spouse/partner" as the perpetrator, were classified as exposed to sexual IPV, and the remaining respondents were classified as non-exposed. Participants categorized as exposed to one or more of the aforementioned types of IPV (emotional, physical, sexual) were also pooled and further categorized as exposed to any IPV, with the remaining respondents classified as non-exposed.

Participants who answered "Yes, as a child" to at least one of the questions "Has anyone ever systematically and over a longer period tried to subdue, degrade, or humiliate you?", "Have you experienced physical attacks/abuse?", and "Have you been sexually abused?" were classified as exposed to any $\mathrm{CV}$, and the remaining respondents were classified as non-exposed.

A four-category, combined IPV/CV variable was then constructed for each type of IPV:

1. "No emotional/physical/sexual/any IPV and no CV",

2. "Any CV, but no emotional/physical/sexual/any IPV ",

3. "Emotional/physical/sexual/any IPV, but no CV"

4. "Emotional/physical/sexual/any IPV and any CV". 
The category "No emotional/physical/sexual/any IPV and no CV" was used as the reference category. However, as a person who has never experienced, for instance, sexual IPV, may have experienced other types of IPV or violence in adulthood from other person than their partner, the reference group "No sexual IPV and no CV" may contain participants who have experienced other types of violence. Sensitivity analyses were therefore performed, using only participants who reported no violent experiences in their lifetime as the reference group.

\section{Mental health problems}

Psychological distress was measured using the HSCL-10, which is primarily comprised of symptoms of anxiety and depression (31). The HSCL-10 addresses respondents' experiences during the previous 4 weeks of: (1) sudden anxiety, (2) anxiousness, (3) dizziness, (4) tension/stress, (5) self-blame, (6) sleeplessness, (7) sadness, (8) worthlessness, (9) finding everything burdensome, and (10) hopelessness. Each item was rated on a 4-point scale, from 1 "Not at all bothered" to 4 "Extremely bothered". For respondents with one or two missing items, missing values were replaced with the sample mean value for each item, as suggested by Strand et al. (31) There were 241 (2.2\%) participants with one missing item and $44(0.4 \%)$ with two missing items. A psychological distress score was then calculated as the mean of the 10 items in HSCL-10, producing a score ranging from 1 to 4 , where 1 indicated no symptoms of anxiety and depression, and 4 indicated severe symptoms. In the final sample, the internal consistency of the psychological distress score was high (Cronbach $a=.90$ ), with no ethnic differences. The score was used as a continuous variable in our study.

Symptoms of PTS during the last 12 months were assessed by posing three questions from the NorAQ: (1) intrusive memories, (2) avoidance of certain situations, and (3) emotional numbness. The four response options ("No", "Yes, but rarely", "Sometimes", and "Often”) were ranked on a 4-point scale, from 1 "No" to 4 "Often". There were $56(0.5 \%)$ participants with missing values on intrusive memories, 77 $(0.7 \%)$ with missing values on avoidance of certain situations, and $105(1.0 \%)$ with missing values on emotional numbness. Missing values were recoded to 1 "No". A PTS score was calculated as the mean of the three items and used as a continuous variable in the analyses.

\section{Background variables}

\section{Laestadian affiliation}

Respondents were asked to indicate their affiliation with any of the following religious/lifestance organizations: "The state church" (Church of Norway), "the Laestadian congregation", "Other religious organization/community", "non-religious life-stance organization/community", "not a member of any religious/life-stance organization". Multiple answered were allowed. Participants who reported that they themselves, their mother, father, or grandparents were affiliated with a Laestadian congregation were classified as Laestadianists. The Laestadian movement is a conservative Lutheran denomination particularly widespread among the Sami in the Northern regions of Norway, Sweden, and Finland. Respondents with no personal or familial affiliation with a Laestadian congregation were classified as 
non-Laestadianists (missing $n=145,1.3 \%$ ). The vast majority of participants were affiliated with the state church.

\section{Municipality of residence}

The 25 municipalities included in the SAMINOR 2 Questionnaire Survey were selected based on the 1970 census in Norway and other relevant knowledge indicating a significant Sami population (32). However, the density of Sami in these municipalities differs. Five municipalities in the former Finnmark County were defined as Sami majority regions (Kautokeino, Karasjok, Porsanger, Tana, and Nesseby). In these municipalities, or in certain areas of the municipality, a majority of the population are of Sami descent, and Sami culture and language is dominant (32). Regions in which Sami were considered a minority were categorized as Sami minority regions and included the remaining municipalities: Røyrvik, Snåsa, Røros, Namsskogan, Narvik, Grane, Hattfjelldal, Tysfjord, Evenes, Skånland, Lavangen, Lyngen, Storfjord, Kåfjord, Kvænangen, Alta, Loppa, Kvalsund, Lebesby, and Sør-Varanger.

\section{Exposure to discrimination}

Respondents were asked about their exposure to discrimination with the following questions: "Have you been subjected to discrimination?". The response options were: "Yes, during last 2 years", "Yes, previously", "No", and "Don't know". The two positive response options were merged. There were 63 missing values $(0.6 \%)$, and they were included in the "No" group.

\section{Alcohol intake}

Respondents were asked to indicate how often they had consumed alcohol in the last year. The eight possible response options were collapsed into three categories: Seldom/never (including the responses "Never consumed alcohol", "Have not been drinking alcohol during the last year", "A few times during the last year"), Monthly ("About once a month", "Two or three times per month"), Weekly ("About once a week", "Two or three times a week", and "Four to seven times a week"). There were 79 missing values for alcohol intake (0.7\%).

\section{Socio-demographic variables}

Age and gender were retrieved from the National Population Registry. Duration of education was used as a proxy for socioeconomic status and was reported in the questionnaire as the completed number of years of education. Age and duration of education were used as continuous variables in multivariable regressions. There were 93 participants with missing values for duration of education $(0.9 \%)$.

\section{Ethics}

The data collection and storage of data were approved by the Norwegian Data Protection Authority (Datatilsynet). Written informed consent was obtained from all participants. The study was approved by the Regional Committee for Medical and Health Research Ethics (REK-Sør-Øst) and the SAMINOR Project Board.

\section{Statistical analysis}


IBM SPSS Statistics Version 26.0 for Windows was used to conduct statistical analyses. Categorical sample characteristics are presented as numbers and percentages, and continuous variables are presented as means and standard deviations, stratified by gender and ethnicity. The Pearson's Chi-square test was used for categorical variables and the two-sample t-test was used for continuous variables for the comparison between Sami and non-Sami. For the continuous psychological distress and PTS scores, means, standard deviations, medians, and 1st and 3rd quartiles are presented. Comparing means of psychological distress and PTS scores between the two ethnicities was performed by two-sample t-tests. A non-parametric test (Wilcoxon rank-sum test) was also performed. Multiple linear regression analyses were conducted with psychological distress score and PTS score, respectively, as dependent variables, and the four-category, combined IPV/CV variables were used as main predictors in separate models. Separate models were run for Sami, non-Sami, and all women, and for emotional, physical, sexual, and any IPV. Due to a low number of men exposed to IPV, only an analysis for any IPV was performed for all men combined. Results are presented as beta coefficients and $p$ values. In each case, two models were run; in model 1, age was included as a possible confounder. In model 2, age, duration of education, Laestadian affiliation, area of residence (Sami majority/Sami minority), exposure to discrimination and alcohol intake were included as possible confounders. We investigated possible interaction between ethnicity and the four-category, combined IPV/CV variables on the two dependent variables reflecting mental health problems. Level of significance was set to $5 \%$.

\section{Results}

Sami women were younger than the non-Sami women (mean age 44.9 and 46.3 years, respectively, $\mathrm{p}$ $<.001$ ), whereas there were no significant ethnic differences in age among men (mean age 49.3). The mean duration of education was 14.6 years for Sami women vs. 13.9 for non-Sami women $(p<.001)$. The corresponding figures for men were 13.0 in both ethnicities $(p=.607)$. Laestadian affiliation was two and a half times more common among Sami as compared to non-Sami. A higher proportion of Sami reported exposure to discrimination compared to non-Sami. Moreover, Sami reported less frequent alcohol intake than non-Sami. (Table 1). 
Table 1

Background characteristics of the study sample by gender and ethnicity: the SAMINOR 2 Questionnaire Survey $(n=10,790)$.

\begin{tabular}{|c|c|c|c|c|c|c|c|c|c|c|}
\hline & \multicolumn{5}{|c|}{ Women $(n=6003)$} & \multicolumn{5}{|c|}{ Men $(n=4787)$} \\
\hline & \multicolumn{2}{|c|}{$\begin{array}{l}\text { Sami }(n= \\
\text { 1197) }\end{array}$} & \multicolumn{3}{|c|}{ non-Sami $(n=4806)$} & \multicolumn{2}{|c|}{$\begin{array}{l}\text { Sami }(n= \\
921)\end{array}$} & \multicolumn{3}{|c|}{ non-Sami $(n=3866)$} \\
\hline & Mean & SD & Mean & SD & $\mathbf{P}^{*}$ & Mean & SD & Mean & SD & $\mathbf{P}^{*}$ \\
\hline Age (years) & 44.9 & 13.9 & 46.3 & 13.5 & .001 & 49.0 & 13.4 & 49.4 & 13.3 & .500 \\
\hline \multirow{2}{*}{$\begin{array}{l}\text { Duration of } \\
\text { education } \\
\text { (years) }\end{array}$} & 14.6 & 3.9 & 13.9 & 3.7 & $<.001$ & 13.0 & 3.8 & 13.0 & 3.7 & .607 \\
\hline & $\mathrm{n}$ & $\%$ & $\mathrm{n}$ & $\%$ & $\mathbf{P}^{*}$ & $\mathbf{n}$ & $\%$ & $\mathbf{n}$ & $\%$ & $P^{*}$ \\
\hline $\begin{array}{l}\text { Laestadianism } \\
\text { affiliation }\end{array}$ & & & & & $<.001$ & & & & & $<.001$ \\
\hline $\begin{array}{l}\text { Non- } \\
\text { Laestadianist }\end{array}$ & 699 & 54.4 & 4015 & 83.5 & & 535 & 58.1 & 3241 & 83.8 & \\
\hline Laestadianist & 498 & 41.6 & 791 & 16.5 & & 386 & 41.9 & 625 & 16.2 & \\
\hline $\begin{array}{l}\text { Municipality of } \\
\text { residence }\end{array}$ & & & & & $<.001$ & & & & & $<.001$ \\
\hline $\begin{array}{l}\text { Sami majority } \\
\text { region }\end{array}$ & 740 & 61.9 & 539 & 11.2 & & 551 & 59.8 & 417 & 10.8 & \\
\hline $\begin{array}{l}\text { Sami minority } \\
\text { region }\end{array}$ & 457 & 38.1 & 4267 & 88.8 & & 370 & 40.2 & 3447 & 89.2 & \\
\hline $\begin{array}{l}\text { Exposed to } \\
\text { discrimination }\end{array}$ & & & & & $<.001$ & & & & & $<.001$ \\
\hline No & 566 & 47.3 & 3855 & 80.2 & & 444 & 48.2 & 3136 & 81.1 & \\
\hline Yes & 505 & 42.2 & 633 & 13.2 & & 372 & 40.4 & 454 & 11.7 & \\
\hline Don't know & 126 & 10.5 & 318 & 6.6 & & 105 & 11.4 & 276 & 7.1 & \\
\hline Alcohol intake & & & & & $<.001$ & & & & & .007 \\
\hline Seldom/never & 520 & 43.2 & 1755 & 36.5 & & 261 & 28.3 & 1025 & 26.5 & \\
\hline Monthly & 451 & 37.7 & 1721 & 35.8 & & 367 & 39.8 & 1393 & 36.0 & \\
\hline Weekly & 226 & 18.9 & 1330 & 27.7 & & 293 & 31.8 & 1448 & 37.5 & \\
\hline
\end{tabular}




\section{Intimate partner violence and childhood violence}

A total of $12.8 \%$ of women and $2.0 \%$ of men reported any IPV. A significantly higher proportion of Sami women reported emotional $(12.4 \%$ vs. $9.5 \%, p=.003)$, physical $(11.6 \%$ vs. $6.9 \%, p<.001)$, and any IPV $(17.2 \%$ vs. $11.8 \%, p<.001)$ compared to non-Sami women. There were no ethnic differences in the reporting of sexual IPV among women ( $2.1 \%$ vs. $1.8 \%, \mathrm{p}=.524)$ (Table 2$)$. Any CV was more commonly reported by Sami than by non-Sami women $(31.2 \%$ vs. $21.6 \%, p<.001)$. Further, exposure to IPV was strongly associated with exposure to $\mathrm{CV}$. Among women who reported any CV, a total of $19.6 \%$ reported IPV, while only $10.8 \%$ of women who did not report CV reported IPV. The same pattern was found among men; $2.5 \%$ reported any IPV among men exposed to $\mathrm{CV}$, as compared with $1.5 \%$ among men not exposed to CV (results not shown in the table).

Among all women in the study sample, $4.6 \%$ reported both any IPV and any CV (Table 2), while the corresponding figure for men was $0.5 \%$ (results not shown in the table). A higher proportion of Sami women reported both emotional IPV and any CV $(5.2 \%$ vs. $3.2 \%, p=.001)$, both physical IPV and any CV $(5.1 \%$ vs. $2.1 \%, p<.001$, ) and both any IPV and any CV $(7.3 \%$ vs. $4.0 \%, p<.001)$ compared to non-Sami women. Very few women $(<1 \%)$ reported both sexual IPV and any CV, with no ethnic differences $(p=.200)$ (Table 2). 
Table 2

Prevalence of IPV and CV among all women and by ethnicity, the SAMINOR 2 Questionnaire Survey $(\mathrm{n}=$ 6003).

\begin{tabular}{|c|c|c|c|c|c|c|c|}
\hline \multirow[b]{2}{*}{ Violence } & \multicolumn{2}{|c|}{$\begin{array}{l}\text { All women }(n= \\
6003)\end{array}$} & \multicolumn{2}{|c|}{$\begin{array}{l}\text { Sami women }(n= \\
\text { 1197) }\end{array}$} & \multicolumn{2}{|c|}{$\begin{array}{l}\text { Non-Sami women ( } \mathrm{n} \\
=4806 \text { ) }\end{array}$} & \multirow[b]{2}{*}{$P^{*}$} \\
\hline & $\mathbf{n}$ & $\%$ & n & $\%$ & $\mathrm{n}$ & $\%$ & \\
\hline Any CV & & & & & & & $<.001$ \\
\hline No & 4591 & 76.5 & 823 & 68.8 & 3768 & 78.4 & \\
\hline Yes & 1412 & 23.5 & 374 & 31.2 & 1038 & 21.6 & \\
\hline Any IPV & & & & & & & $<.001$ \\
\hline No & 5232 & 87.2 & 991 & 82.8 & 4241 & 88.2 & \\
\hline Yes & 771 & 12.8 & 206 & 17.2 & 565 & 11.8 & \\
\hline Emotional IPV (Yes) & 603 & 10.0 & 148 & 12.4 & 455 & 9.5 & .003 \\
\hline Physical IPV (Yes) & 470 & 7.8 & 139 & 11.6 & 331 & 6.9 & $<.001$ \\
\hline Sexual IPV (Yes) & 112 & 1.9 & 25 & 2.1 & 87 & 1.8 & .524 \\
\hline $\begin{array}{l}\text { Emotional IPV and/or } \\
\text { any CV }\end{array}$ & & & & & & & $<.001$ \\
\hline $\begin{array}{l}\text { No emotional IPV } \\
\text { and no CV }\end{array}$ & 4203 & 70.0 & 737 & 61.6 & 3466 & 72.1 & \\
\hline $\begin{array}{l}\text { Any CV, but no } \\
\text { emotional IPV }\end{array}$ & 1197 & 19.9 & 312 & 26.1 & 885 & 18.4 & \\
\hline $\begin{array}{l}\text { Emotional IPV, but no } \\
\mathrm{CV}\end{array}$ & 388 & 6.5 & 86 & 7.2 & 302 & 6.3 & \\
\hline $\begin{array}{l}\text { Emotional IPV and } \\
\text { any CV }\end{array}$ & 215 & 3.6 & 62 & 5.2 & 153 & 3.2 & \\
\hline $\begin{array}{l}\text { Physical IPV and/or any } \\
\text { CV }\end{array}$ & & & & & & & $<.001$ \\
\hline $\begin{array}{l}\text { No physical IPV and } \\
\text { no CV }\end{array}$ & 4285 & 71.4 & 745 & 62.2 & 3540 & 73.7 & \\
\hline $\begin{array}{l}\text { Any CV, but no } \\
\text { physical IPV }\end{array}$ & 1248 & 20.8 & 313 & 26.1 & 935 & 19.5 & \\
\hline $\begin{array}{l}\text { Physical IPV, but no } \\
\text { CV }\end{array}$ & 306 & 5.1 & 78 & 6.5 & 228 & 4.7 & \\
\hline
\end{tabular}

Abbreviations: IPV, intimate partner violence; CV, childhood violence.

* Comparing Sami and non-Sami by Pearson's chi-squared test. 


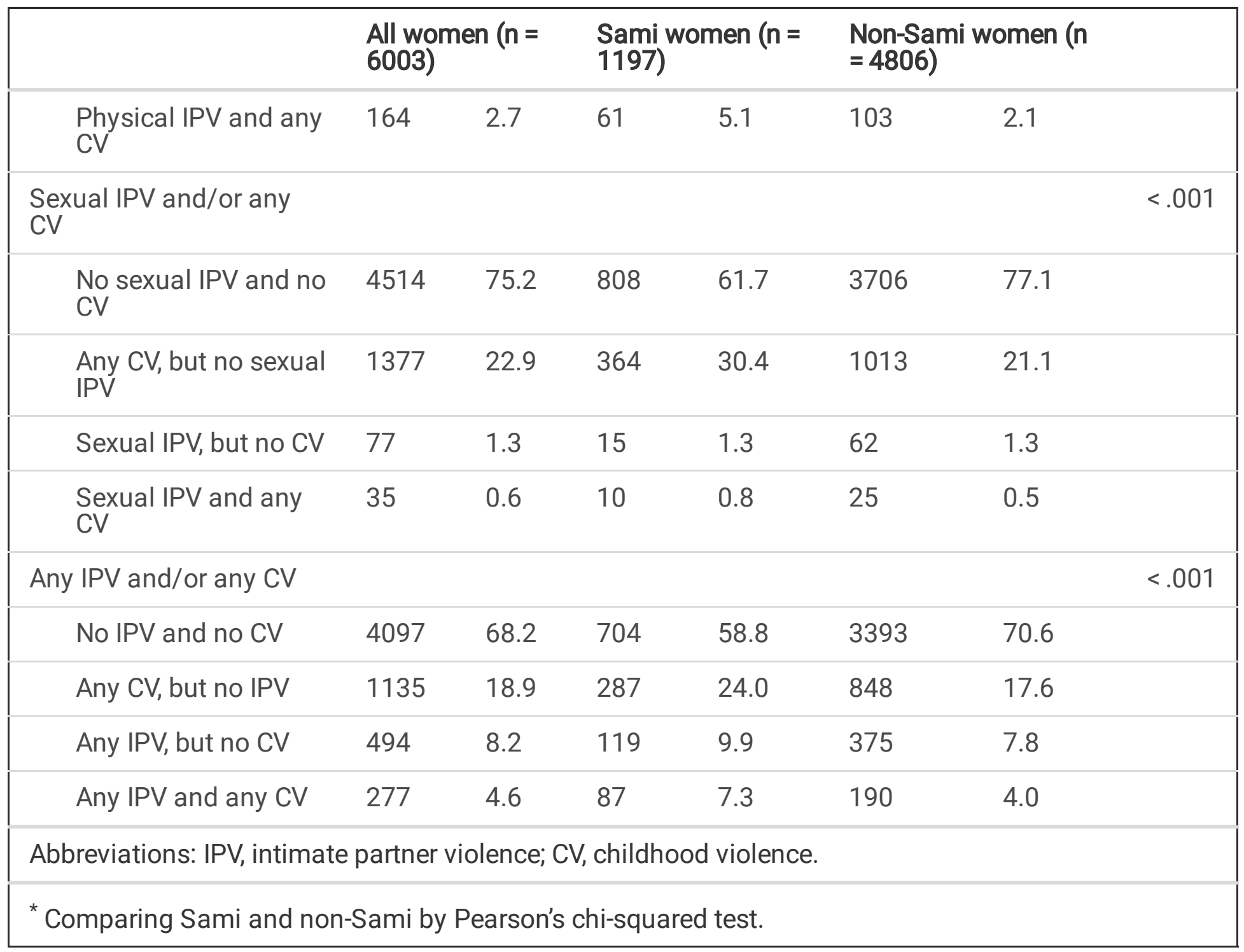

\section{Mental health problems}

The mean psychological distress score was slightly higher among Sami women (1.40) compared to nonSami women (1.37) ( $p=.034)$ (Table 3). However, the distribution was skewed, and the median was found to be 1.20 in both ethnicities. Despite the equal median, the distributions were significantly different, with a higher portion of Sami in the upper part of the scale $(p<.001$ in Wilcoxon rank-sum test). The same pattern was observed for PTS score, with a mean of 1.61 and 1.49 for Sami and non-Sami women, respectively $(p<.001)$, and median of 1.33 in both ethnicities $(p<.001)$ (Table 4$)$. When looking at the combined IPV/CV variables, participants that reported IPV or CV had higher mean and median psychological distress and PTS scores compared to the group reporting no IPV and no CV (Tables 3 \& 4). This was observed for emotional, physical, sexual, and any IPV, with similar results for Sami and nonSami women. Those who reported both IPV and CV had the highest mean values. The lowest mean was reported by those reporting no IPV and no CV. 
Table 3

Mean and median HSCL-10 score by different types of violence among Sami and non-Sami women, the SAMINOR 2 Questionnaire Survey $(n=6003)$.

\begin{tabular}{|c|c|c|c|c|c|c|c|c|c|c|}
\hline & \multicolumn{5}{|c|}{ Sami women=1197 } & \multicolumn{5}{|c|}{ Non-Sami women=4806 } \\
\hline & $\mathrm{n}$ & Mean & SD & Median & Q1-Q3 & $\mathrm{n}$ & Mean & SD & Median & Q1-Q3 \\
\hline HSCL-10 score & 1197 & $1.40^{\mathrm{a}}$ & .497 & $1.20^{\mathrm{b}}$ & $\begin{array}{l}1.0- \\
1.6\end{array}$ & 4806 & $1.37^{a}$ & .486 & $1.20^{\mathrm{b}}$ & $\begin{array}{l}1.0- \\
1.5\end{array}$ \\
\hline \multicolumn{11}{|l|}{ Emotional } \\
\hline $\begin{array}{l}\text { No emotional } \\
\text { IPV and no CV }\end{array}$ & 737 & 1.28 & .382 & 1.10 & $\begin{array}{l}1.1- \\
1.4\end{array}$ & 3466 & 1.28 & .380 & 1.10 & $\begin{array}{l}1.1- \\
1.4\end{array}$ \\
\hline $\begin{array}{l}\text { Any CV, but no } \\
\text { emotional IPV }\end{array}$ & 312 & 1.54 & .551 & 1.40 & $\begin{array}{l}1.1- \\
1.8\end{array}$ & 885 & 1.59 & .631 & 1.40 & $\begin{array}{l}1.1- \\
1.9\end{array}$ \\
\hline $\begin{array}{l}\text { Emotional IPV, } \\
\text { but no CV }\end{array}$ & 86 & 1.57 & .560 & 1.40 & $\begin{array}{l}1.1- \\
1.8\end{array}$ & 302 & 1.51 & .553 & 1.40 & $\begin{array}{l}1.1- \\
1.7\end{array}$ \\
\hline $\begin{array}{l}\text { Emotional IPV } \\
\text { and any CV }\end{array}$ & 62 & 1.94 & .697 & 1.80 & $\begin{array}{l}1.4- \\
2.4\end{array}$ & 153 & 1.81 & .736 & 1.60 & $\begin{array}{l}1.2- \\
2.3\end{array}$ \\
\hline \multicolumn{11}{|l|}{ Physical } \\
\hline $\begin{array}{l}\text { No physical IPV } \\
\text { and no CV }\end{array}$ & 745 & 1.28 & .389 & 1.10 & $\begin{array}{l}1.0- \\
1.4\end{array}$ & 3540 & 1.28 & .387 & 1.10 & $\begin{array}{l}1.1- \\
1.4\end{array}$ \\
\hline $\begin{array}{l}\text { Any CV, but no } \\
\text { physical IPV }\end{array}$ & 313 & 1.54 & .528 & 1.40 & $\begin{array}{l}1.1- \\
1.8\end{array}$ & 935 & 1.60 & .629 & 1.40 & $\begin{array}{l}1.1- \\
1.9\end{array}$ \\
\hline $\begin{array}{l}\text { Physical IPV, } \\
\text { but no CV }\end{array}$ & 78 & 1.54 & .546 & 1.40 & $\begin{array}{l}1.1- \\
1.8\end{array}$ & 228 & 1.48 & .556 & 1.30 & $\begin{array}{l}1.1- \\
1.7\end{array}$ \\
\hline $\begin{array}{l}\text { Physical IPV } \\
\text { and any CV }\end{array}$ & 61 & 1.93 & .788 & 1.80 & $\begin{array}{l}1.2- \\
2.4\end{array}$ & 103 & 1.83 & .805 & 1.60 & $\begin{array}{l}1.2- \\
2.3\end{array}$ \\
\hline \multicolumn{11}{|l|}{ Sexual } \\
\hline $\begin{array}{l}\text { No sexual IPV } \\
\text { and no CV }\end{array}$ & 808 & 1.30 & .404 & 1.20 & $\begin{array}{l}1.0- \\
1.4\end{array}$ & 3706 & 1.29 & .395 & 1.20 & $\begin{array}{l}1.0- \\
1.4\end{array}$ \\
\hline $\begin{array}{l}\text { Any CV, but no } \\
\text { sexual IPV }\end{array}$ & 364 & 1.60 & .595 & 1.40 & $\begin{array}{l}1.1- \\
1.9\end{array}$ & 1013 & 1.61 & .637 & 1.40 & $\begin{array}{l}1.1- \\
1.9\end{array}$ \\
\hline $\begin{array}{l}\text { Sexual IPV, but } \\
\text { no CV }\end{array}$ & 15 & 1.69 & .680 & 1.50 & $\begin{array}{l}1.0- \\
2.1\end{array}$ & 62 & 1.54 & .660 & 1.30 & $\begin{array}{l}1.0- \\
1.9\end{array}$ \\
\hline
\end{tabular}

Abbreviations: HSCL-10 score, Hopkins Symptom Checklist score of 10 questions; SD, standard deviation; Q1, first quartile; Q3, third quartile; IPV, intimate partner violence; CV, childhood violence.

Notes: ${ }^{a} p=0.034$ comparing means with independent samples t-test, ${ }^{b} p<0.001$ comparing the distributions non-parametrically with Wilcoxon rank-sum test. 


\begin{tabular}{|c|c|c|c|c|c|c|c|c|c|c|}
\hline \multirow[b]{2}{*}{$\begin{array}{l}\text { Sexual IPV and } \\
\text { any CV }\end{array}$} & \multicolumn{5}{|c|}{ Sami women=1197 } & \multicolumn{5}{|c|}{ Non-Sami women=4806 } \\
\hline & 10 & 1.70 & .614 & 1.80 & $\begin{array}{l}1.1- \\
2.2\end{array}$ & 25 & 2.21 & .943 & 2.20 & $\begin{array}{l}1.3- \\
2.8\end{array}$ \\
\hline \multicolumn{11}{|l|}{ Any } \\
\hline $\begin{array}{l}\text { No IPV and no } \\
\text { CV }\end{array}$ & 704 & 1.27 & .382 & 1.10 & $\begin{array}{l}1.0- \\
1.4\end{array}$ & 3393 & 1.28 & .379 & 1.10 & $\begin{array}{l}1.0- \\
1.4\end{array}$ \\
\hline $\begin{array}{l}\text { Any CV, but no } \\
\text { IPV }\end{array}$ & 278 & 1.52 & .528 & 1.30 & $\begin{array}{l}1.1- \\
1.8\end{array}$ & 848 & 1.59 & .633 & 1.40 & $\begin{array}{l}1.1- \\
1.9\end{array}$ \\
\hline $\begin{array}{l}\text { Any IPV, but no } \\
\text { CV }\end{array}$ & 119 & 1.52 & .518 & 1.40 & $\begin{array}{l}1.1- \\
1.8\end{array}$ & 375 & 1.48 & .536 & 1.30 & $\begin{array}{l}1.1- \\
1.7\end{array}$ \\
\hline $\begin{array}{l}\text { Any IPV and } \\
\text { any CV }\end{array}$ & 87 & 1.89 & .709 & 1.80 & $\begin{array}{l}1.3- \\
2.4\end{array}$ & 190 & 1.77 & .717 & 1.50 & $\begin{array}{l}1.2- \\
2.2\end{array}$ \\
\hline \multicolumn{11}{|c|}{$\begin{array}{l}\text { Abbreviations: HSCL-10 score, Hopkins Symptom Checklist score of } 10 \text { questions; SD, standard } \\
\text { deviation; Q1, first quartile; Q3, third quartile; IPV, intimate partner violence; CV, childhood violence. }\end{array}$} \\
\hline
\end{tabular}


Table 4

Mean and median PTS score by different types of violence among Sami and non-Sami women, the SAMINOR 2 Questionnaire Survey $(n=6003)$.

\begin{tabular}{|c|c|c|c|c|c|c|c|c|c|c|}
\hline & \multicolumn{5}{|c|}{ Sami women=1197 } & \multicolumn{5}{|c|}{ Non-Sami women=4806 } \\
\hline & $n$ & Mean & SD & Median & Q1-Q3 & $n$ & Mean & SD & Median & Q1-Q3 \\
\hline PTS score & 1197 & $1.61^{\mathrm{a}}$ & .678 & $1.33^{b}$ & $\begin{array}{l}1.0- \\
2.0\end{array}$ & 4806 & $1.49^{a}$ & .639 & $1.33^{b}$ & $\begin{array}{l}1.0- \\
1.7\end{array}$ \\
\hline \multicolumn{11}{|l|}{$\begin{array}{l}\text { Emotional IPV and } \\
\text { any CV }\end{array}$} \\
\hline $\begin{array}{l}\text { No emotional } \\
\text { IPV and no CV }\end{array}$ & 737 & 1.45 & .698 & 1.30 & $\begin{array}{l}1.0- \\
1.7\end{array}$ & 3466 & 1.37 & .541 & 1.00 & $\begin{array}{l}1.0- \\
1.7\end{array}$ \\
\hline $\begin{array}{l}\text { Any CV, but no } \\
\text { emotional IPV }\end{array}$ & 312 & 1.79 & .703 & 1.70 & $\begin{array}{l}1.3- \\
2.3\end{array}$ & 885 & 1.78 & .747 & 1.70 & $\begin{array}{l}1.0- \\
2.3\end{array}$ \\
\hline $\begin{array}{l}\text { Emotional IPV, } \\
\text { but no CV }\end{array}$ & 86 & 1.81 & .698 & 1.70 & $\begin{array}{l}1.3- \\
2.3\end{array}$ & 302 & 1.77 & .716 & 1.70 & $\begin{array}{l}1.0- \\
2.3\end{array}$ \\
\hline $\begin{array}{l}\text { Emotional IPV } \\
\text { and any CV }\end{array}$ & 62 & 2.24 & .872 & 2.00 & $\begin{array}{l}1.3- \\
2.8\end{array}$ & 153 & 2.04 & .849 & 2.00 & $\begin{array}{l}1.3- \\
2.7\end{array}$ \\
\hline \multicolumn{11}{|l|}{$\begin{array}{l}\text { Physical IPV and } \\
\text { any CV }\end{array}$} \\
\hline $\begin{array}{l}\text { No physical IPV } \\
\text { and no CV }\end{array}$ & 745 & 1.46 & .589 & 1.30 & $\begin{array}{l}1.0- \\
1.7\end{array}$ & 3540 & 1.34 & .549 & 1.00 & $\begin{array}{l}1.0- \\
1.7\end{array}$ \\
\hline $\begin{array}{l}\text { Any CV, but no } \\
\text { physical IPV }\end{array}$ & 313 & 1.80 & .712 & 1.70 & $\begin{array}{l}1.3- \\
2.3\end{array}$ & 935 & 1.78 & .747 & 1.70 & $\begin{array}{l}1.0- \\
2.3\end{array}$ \\
\hline $\begin{array}{l}\text { Physical IPV, } \\
\text { but no CV }\end{array}$ & 78 & 1.77 & .713 & 1.70 & $\begin{array}{l}1.3- \\
2.3\end{array}$ & 228 & 1.75 & .719 & 1.70 & $\begin{array}{l}1.0- \\
2.0\end{array}$ \\
\hline $\begin{array}{l}\text { Physical IPV } \\
\text { and any CV }\end{array}$ & 61 & 2.19 & .868 & 2.00 & $\begin{array}{l}1.3- \\
2.7\end{array}$ & 103 & 2.13 & .887 & 2.00 & $\begin{array}{l}1.3- \\
3.0\end{array}$ \\
\hline \multicolumn{11}{|l|}{$\begin{array}{l}\text { Sexual IPV and any } \\
\text { CV }\end{array}$} \\
\hline $\begin{array}{l}\text { No sexual IPV } \\
\text { and no CV }\end{array}$ & 808 & 1.48 & .604 & 1.30 & $\begin{array}{l}1.0- \\
1.7\end{array}$ & 3706 & 1.40 & .562 & 1.00 & $\begin{array}{l}1.0- \\
1.7\end{array}$ \\
\hline
\end{tabular}

Abbreviations: PTS, post-traumatic stress; SD, standard deviation; ; Q1, first quartile; Q3, third quartile; IPV, intimate partner violence; CV, childhood violence.

Notes: ${ }^{a}$ comparing means with independent samples t-test, $p<0.001,{ }^{b}$ Comparing the distributions non-parametrically with Wilcoxon rank-sum test, $p<0.001$. 


\begin{tabular}{|c|c|c|c|c|c|c|c|c|c|c|}
\hline \multirow[b]{2}{*}{$\begin{array}{l}\text { Any CV, but no } \\
\text { sexual IPV }\end{array}$} & \multicolumn{5}{|c|}{ Sami women=1197 } & \multicolumn{5}{|c|}{ Non-Sami women=4806 } \\
\hline & 364 & 1.85 & .748 & 1.70 & $\begin{array}{l}1.3- \\
2.3\end{array}$ & 1013 & 1.80 & .762 & 1.70 & $\begin{array}{l}1.3- \\
2.3\end{array}$ \\
\hline $\begin{array}{l}\text { Sexual IPV, but } \\
\text { no CV }\end{array}$ & 15 & 1.91 & .728 & 1.70 & $\begin{array}{l}1.3- \\
2.7\end{array}$ & 62 & 1.77 & .731 & 1.70 & $\begin{array}{l}1.0- \\
2.3\end{array}$ \\
\hline $\begin{array}{l}\text { Sexual IPV and } \\
\text { any CV }\end{array}$ & 10 & 2.26 & .813 & 2.30 & $\begin{array}{l}1.6- \\
2.8\end{array}$ & 25 & 2.28 & .874 & 2.30 & $\begin{array}{l}1.7- \\
3.0\end{array}$ \\
\hline \multicolumn{11}{|l|}{$\begin{array}{l}\text { Any IPV and } \\
\text { any CV }\end{array}$} \\
\hline $\begin{array}{l}\text { No IPV and no } \\
\text { CV }\end{array}$ & 704 & 1.45 & .583 & 1.30 & $\begin{array}{l}1.0- \\
1.7\end{array}$ & 3393 & 1.37 & .539 & 1.00 & $\begin{array}{l}1.0- \\
1.7\end{array}$ \\
\hline $\begin{array}{l}\text { Any CV, but no } \\
\text { IPV }\end{array}$ & 278 & 1.77 & .696 & 1.70 & $\begin{array}{l}1.3- \\
1.7\end{array}$ & 848 & 1.78 & .749 & 1.70 & $\begin{array}{l}1.0- \\
2.3\end{array}$ \\
\hline $\begin{array}{l}\text { Any IPV, but no } \\
\text { CV }\end{array}$ & 119 & 1.73 & .694 & 1.70 & $\begin{array}{l}1.3- \\
2.3\end{array}$ & 375 & 1.73 & .701 & 1.70 & $\begin{array}{l}1.0- \\
2.0\end{array}$ \\
\hline $\begin{array}{l}\text { Any IPV and } \\
\text { any CV }\end{array}$ & 87 & 2.16 & .851 & 2.00 & $\begin{array}{l}1.3- \\
2.7\end{array}$ & 190 & 1.99 & .825 & 2.00 & $\begin{array}{l}1.3- \\
2.7\end{array}$ \\
\hline \multicolumn{11}{|c|}{$\begin{array}{l}\text { Abbreviations: PTS, post-traumatic stress; SD, standard deviation; ; Q1, first quartile; Q3, third quartile; } \\
\text { IPV, intimate partner violence; CV, childhood violence. }\end{array}$} \\
\hline \multicolumn{11}{|c|}{$\begin{array}{l}\text { Notes: }{ }^{\text {a }} \text { comparing means with independent samples t-test, } \mathrm{p}<0.001,{ }^{\mathrm{b}} \text { Comparing the distributions } \\
\text { non-parametrically with Wilcoxon rank-sum test, } \mathrm{p}<0.001 \text {. }\end{array}$} \\
\hline
\end{tabular}

There were no significant interactions between ethnicity and the combined IPV/CV variables on either psychological distress score or PTS score. Hence, results from the regression analyses for all women combined are presented in Tables $5 \& 6$. When adjusting for age in model 1 , all types of IPV were strongly associated with psychological distress and PTS scores compared to the group reporting no IPV and no $\mathrm{CV}$, with the highest scores observed for those reporting both IPV and CV. In model 2, adjusting for five additional possible confounders (Laestadian affiliation, municipality of residence, exposure to discrimination, alcohol intake, age, and duration of education), the strength of the relationships was reduced but remained significant (Tables $5 \& 6$ ). When investigating the association between the combined IPV/CV variables and mental health among men, the analyses were performed among all men and for any IPV only, due to small numbers and no significant interaction between ethnicity and the combined variable of any IPV and any CV on psychological distress score or on PTS score. Age-adjusted analyses demonstrated statistically significantly higher mean psychological distress scores in men who reported no IPV and any CV (score 0.24 higher), any IPV but no CV (score 0.26 higher), or any IPV and any CV (score 0.66 higher) than in men who had not experienced IPV or CV (all p-values <.001). Higher mean 
PTS scores were also found in men who reported no IPV and any CV (score 0.50 higher), any IPV but no CV (score 0.40 higher), or any IPV and any CV (score 0.80 higher) than in men who had not experienced IPV or CV (all p-values <.001) (results not shown).

Sensitivity analyses that used only participants who reported no violent experiences in their lifetime as the reference group, and analyses that used the alternative ethnic classification, did not render results that changed the conclusions. 
Table 5

Association between HSCL-10 score and IPV and CV among women, the SAMINOR 2 Questionnaire Survey.

\begin{tabular}{|c|c|c|c|c|}
\hline \multirow{2}{*}{$\begin{array}{l}\text { All women }(n=6003) \\
\text { Predictors }\end{array}$} & \multicolumn{2}{|c|}{ Model $1(n=6003)$} & \multicolumn{2}{|c|}{ Model $2(n=5836)$} \\
\hline & B & P-value & B & P-value \\
\hline \multicolumn{5}{|l|}{ Emotional IPV and any CV } \\
\hline No emotional IPV and no CV & 0 & & 0 & \\
\hline Any CV, but no emotional IPV & .283 & $<.001$ & .244 & $<.001$ \\
\hline Emotional IPV, but no CV & .244 & $<.001$ & .213 & $<.001$ \\
\hline Emotional IPV and any CV & .552 & $<.001$ & .462 & $<.001$ \\
\hline \multicolumn{5}{|l|}{ Physical IPV and any CV } \\
\hline No physical IPV and no CV & 0 & & 0 & \\
\hline Any CV, but no physical IPV & .283 & $<.001$ & .241 & $<.001$ \\
\hline Physical IPV, but no CV & .221 & $<.001$ & .183 & $<.001$ \\
\hline Physical IPV and any CV & .575 & $<.001$ & .498 & $<.001$ \\
\hline \multicolumn{5}{|l|}{ Sexual IPV and any CV } \\
\hline No sexual IPV and no CV & 0 & & 0 & \\
\hline Any CV, but no sexual IPV & .296 & $<.001$ & .252 & $<.001$ \\
\hline Sexual IPV, but no CV & .278 & $<.001$ & .206 & $<.001$ \\
\hline Sexual IPV and any CV & .755 & $<.001$ & .606 & $<.001$ \\
\hline \multicolumn{5}{|l|}{ Any IPV and any CV } \\
\hline No IPV and no CV & 0 & & 0 & \\
\hline Any CV, but no IPV & .280 & $<.001$ & .243 & $<.001$ \\
\hline Any IPV, but no CV & .218 & $<.001$ & .189 & $<.001$ \\
\hline Any IPV and any CV & .514 & $<.001$ & .432 & $<.001$ \\
\hline \multicolumn{5}{|c|}{$\begin{array}{l}\text { Abbreviations: HSCL-10 score, Hopkins Symptom Checklist score of } 10 \text { questions; IPV, intimate } \\
\text { partner violence; CV, childhood violence; B, linear regression coefficient. Notes: Model } 1 \text { : adjusted for } \\
\text { age, Model 2: adjusted for age, duration of education, Laestadian affiliation, municipality of residence } \\
\text { exposure to discrimination and alcohol intake,. Mean score for no emotional IPV and no CV, no } \\
\text { physical IPV and no CV: } 1.28 \text {, no sexual IPV and no CV: } 1.29 \text { and no any IPV and no CV: } 1.37\end{array}$} \\
\hline
\end{tabular}


Table 6

The association between PTS score and IPV and CV among women, the SAMINOR 2 Questionnaire Survey.

\begin{tabular}{|c|c|c|c|c|}
\hline \multirow{2}{*}{$\begin{array}{l}\text { All women }(n=6003) \\
\text { Predictors }\end{array}$} & \multicolumn{2}{|c|}{ Model $1(n=6003)$} & \multicolumn{2}{|c|}{ Model $2(n=5836)$} \\
\hline & B & P-value & B & P-value \\
\hline \multicolumn{5}{|l|}{ Emotional IPV and any CV } \\
\hline No emotional IPV and no CV & 0 & & 0 & \\
\hline Any CV, but no emotional IPV & .379 & $<.001$ & .324 & $<.001$ \\
\hline Emotional IPV, but no CV & .392 & $<.001$ & .354 & $<.001$ \\
\hline Emotional IPV and any CV & 698 & $<.001$ & .598 & $<.001$ \\
\hline \multicolumn{5}{|l|}{ Physical IPV and any CV } \\
\hline No physical IPV and no CV & 0 & & 0 & \\
\hline Any CV, but no physical IPV & .375 & $<.001$ & .318 & $<.001$ \\
\hline Physical IPV, but no CV & .369 & $<.001$ & .319 & $<.001$ \\
\hline Physical IPV and any CV & .745 & $<.001$ & .643 & $<.001$ \\
\hline \multicolumn{5}{|l|}{ Sexual IPV and any CV } \\
\hline No sexual IPV and no CV & 0 & & 0 & \\
\hline Any CV, but no sexual IPV & .389 & $<.001$ & .329 & $<.001$ \\
\hline Sexual IPV, but no CV & .395 & $<.001$ & .313 & $<.001$ \\
\hline Sexual IPV and any CV & .842 & $<.001$ & .662 & $<.001$ \\
\hline \multicolumn{5}{|l|}{ Any IPV and any CV } \\
\hline No IPV and no CV & 0 & & 0 & \\
\hline Any CV, but no IPV & .378 & $<.001$ & .325 & $<.001$ \\
\hline Any IPV, but no CV & .345 & $<.001$ & .307 & $<.001$ \\
\hline Any IPV and any CV & .647 & $<.001$ & .549 & $<.001$ \\
\hline \multicolumn{5}{|c|}{$\begin{array}{l}\text { Abbreviations: PTS, post-traumatic stress; IPV, intimate partner violence; CV, childhood violence; } \mathrm{B} \text {, } \\
\text { linear regression coefficient. }\end{array}$} \\
\hline $\begin{array}{l}\text { Notes: Model 1: adjusted for a } \\
\text { affiliation, municipality of resi } \\
\text { emotional IPV and no CV: } 1.3 \\
\text { no any IPV and no CV: } 1.39 .\end{array}$ & $\begin{array}{l}\text { Idjuste } \\
\text { Ire to c } \\
\text { IPV ar }\end{array}$ & $\begin{array}{l}\text { ge, durat } \\
\text { ination at } \\
\text { in: } 1.40, n\end{array}$ & $\begin{array}{l}\text { ducatio } \\
\text { ol inta } \\
\text { I IPV a }\end{array}$ & $\begin{array}{l}\text { estadian } \\
\text { ean score for no } \\
\text { CV: } 1.41 \text {, and }\end{array}$ \\
\hline
\end{tabular}




\section{Discussion}

This is the first study to present findings on the prevalence of IPV, the association between IPV and mental health problems, and the joint effect of IPV and CV on mental health problems in a Sami compared to a non-Sami population. The study also presents finding on IPV among men, which is an important contribution to the literature on IPV, as most studies are conducted among women only. We found a higher prevalence of IPV among Sami women compared to non-Sami women, and among all women compared to all men. IPV was more commonly reported among those who reported any CV compared to those who did not report CV. The study demonstrates that emotional, physical, and sexual IPV are all associated with mental health problems. The most severe problems were observed among those who reported both IPV and any CV. There were no ethnic differences in the associations between the different types of IPV and mental health problems, and we observed overall similar results for men as for women.

The prevalence of interpersonal violence differs between and within countries, and most studies have been conducted among women (33). The first national study on IPV in Norway was conducted in 20032004 and found a lifetime prevalence of $26.8 \%$ among women (mild, moderate, severe physical and/or sexual violence), which is far higher than the prevalence found in this study (13\%) (17). This difference in prevalence may be partly explained by the fact that the latter study was performed among ever-partnered women, while we do not have information on marital status in the SAMINOR 2 Questionnaire survey. The latter study found a prevalence of $13.9 \%$ for any moderate violence. A national study in Norway from 2013 showed a prevalence of mild physical IPV of 14.2\% for women and 16.3\% for men (no significant difference) (18). For both severe and less severe physical violence combined, the numbers were lower; $9.2 \%$ among women and $1.9 \%$ among men. For sexual violence, the numbers were $5.5 \%$ and $0.5 \%$, respectively (other types of sexual violence except rape). Rape carried out by a current or former intimate partner was reported by $3.8 \%$ of women and $0.1 \%$ of men (18). In comparison, our study found a prevalence of $7.8 \%$ for physical IPV among women and $0.4 \%$ for men. In addition, the prevalence of sexual IPV in our study was lower ( $1.9 \%$ for women and $0 \%$ for men) than that reported in the national study. The national study did not investigate emotional IPV. The above comparisons suggest that the prevalence in our study may be conservative and not inflated. Whether the differences in prevalence are explained by changes over time, regional differences, or design aspects, is difficult to assess.

A higher prevalence of IPV among indigenous populations compared to the dominant group in their countries has been demonstrated in international studies $(21,22,34)$. The present results of a higher prevalence of IPV among Sami women are, therefore, in line with other studies comparing indigenous populations with the majority population in their countries. However, the observed prevalence of IPV among Sami women was far lower than that reported in studies of indigenous women in Canada, which found that indigenous women report the highest rates of IPV in the nation (22).

Several researchers have argued that the differences in the prevalence of IPV and mental health problems among indigenous compared to non-indigenous populations are due to the large cultural consequences 
of colonization, which have left some indigenous populations to suffer from poorer social conditions and low access to health care services $(23,35)$. However, research has shown that, in terms of health, the Sami are in a positive position compared to other indigenous populations $(35,36)$. Our study found that the mean duration of education was higher for Sami compared to non-Sami women, while no difference was observed between Sami and non-Sami men. In Norway, the educational and health care system is, for the most part, free of charge for all Norwegian residents. This might explain the relatively small ethnic differences in socioeconomic status in Norway, as well as the low prevalence of and the relatively small differences in IPV between Sami and non-Sami found in this study. However, social inequalities are increasing in Norway.

The fact that we observed similar results in Sami and non-Sami women with respect to the associations between IPV and/or CV and psychological distress and symptoms of PTS strengthens the assumption that violent victimization generally affects women`s mental health regardless of ethnic background (10, $33,37,38)$. The overall results for men resembled those for women, which highlights that, regardless of gender, IPV and CV affects mental health negatively. Further, the findings of higher psychological distress and PTS scores among those reporting both IPV and CV also strengthen previous findings that the joint effect of CV and later IPV seems to have a more severe effect on mental health $(14,39)$. Since respondents exposed to violence could indicate their relationship with the perpetrator using alternatives other than intimate partner (Stranger, Family/relative, or Other acquaintance), the reference group contained both respondents with no violent experiences and respondents exposed to violence from someone other than an intimate partner, which probably attenuated the relationships. Sensitivity analyses were therefore performed using only participants who reported no violent experiences in their lifetime as the reference group, and the results did not change the conclusions. Early life experiences of violence has been cited as a risk factor for IPV $(14,15)$. This is in line with our results, which showed huge differences in the proportion of participants reporting IPV among those exposed to CV, compared to those not exposed to CV. In order to prevent this inter-generational circle of violence, interventions are needed to address $\mathrm{CV}$.

\section{Strengths And Limitations}

This study had a cross-sectional design that limits the potential for assessing a causal link between the different types of violence and mental health problems. However, exposure to CV is likely to have taken place prior to the reported mental health problems.

The HSCL-10 is widely considered a reliable and valid instrument to measure psychological distress (31) and has also been validated in a Sami population (40). This must be regarded as a strength of the study. The mean HSCL-10 score in our study among non-Sami respondents is in line with the mean value of the HSCL-25 in a national study (41). This suggests that our estimates are valid. However, only three questions from the NorAQ were used to assess symptoms of PTS. Although these questions cover core symptoms included in the Diagnostic and Statistical Manual of Mental Disorders (DSM-V), they are not sufficient to meet all the DSM-V criteria for a PTSD diagnosis. A major limitation is that the PTS 
questions were not asked in response to a specific stressor. Hence, we do not know whether the reported exposure is a traumatic event according to the criteria in the DSM-V for the PTSD diagnosis. Despite this major limitation, the internal consistency of these items was acceptable (Cronbach's alpha 0.75) for both ethnicities, strengthening the reliability of the measurements. However, more items measuring symptoms of PTS would strengthen the validity of the instrument. The three NorAQ questions we used have also been used in other studies $(38,42)$. The questions used to assess violence were also taken from the NorAQ. A validation study among women and men showed that the NorAQ had good validity and reliability (43). However, the questions used in this study represent a modified version of the NorAQ, and they have not been validated in the Sami population or in the non-Sami population in rural Northern Norway. Thus, differences in cultural and linguistic interpretations may have influenced the observed differences between the two groups. However, the questions were formulated rather widely, which may reduce potential bias based on cultural differences. Potential misclassification in the Sami group is unlikely, as studies have found Sami self-identification to be relatively stable (44). However, due to harsh assimilation policies, many Sami have abandoned or denied their Sami ethnicity. A potential misclassification of Sami into the non-Sami group might therefore be in operation, and the association between ethnicity and mental health problems may be attenuated. There is no official register of Sami ethnicity in Norway, and no consensus on how to define Sami ethnicity. Other studies have used different criteria to define the Sami groups. Therefore, we conducted additional analyses using an alternative ethnic categorization, in which we included the criteria "My ethnic background is Sami" to our definition of Sami ethnicity. This definition is used in several papers $(29,45,46)$. Further, we conducted additional analyses with a reference group who reported no violent experiences in their lifetime. The strength of the association with mental health problems did not considerably change in these sensitivity analyses, which is considered a strength of the study.

Due to the low participation rate in the SAMINOR 2 Questionnaire Survey, selection bias is likely, and the results must be interpreted with caution. We have limited information about non-respondents, namely that participation increased with age, and more women than men participated (28). Furthermore, a comparison has been made between respondents and non-respondents of the SAMINOR 2 Questionnaire Survey among invitees who had previously participated in the SAMINOR 1 Survey (28). It was found that, compared to the non-respondents, the respondents had a higher education level and higher family income. Since ethnicity is not recorded in any official register in Norway, we were not able to assess whether the proportion of non-respondents differed in Sami and non-Sami. However, the aforementioned comparison among participants in SAMINOR 1 showed no difference in response rates between Sami and non-Sami.

A general tendency to underreport CV (41) may have introduced recall bias, thus diminishing the association with adult mental health problems. On the other hand, current anxiety and depression might increase the tendency to recollect and report life events in a more negative and traumatic way (47), thus strengthening the association with mental health problems. Recall bias on the outcome variables is considered to be of minor importance, as the respondents were asked about recent mental health. 


\section{Conclusion}

The present findings demonstrate that exposure to emotional, physical, or sexual IPV is strongly associated with mental health problems. The most severe mental health problems were observed for those who were exposed to both IPV and CV. It is therefore important for victims of IPV to address experiences of violence that occurred earlier in life. The different types of IPV (emotional, physical, and sexual) had quite similar effects on mental health problems. Results for Sami and non-Sami women did not differ, and overall, we observed the same pattern for men as well. A higher proportion of Sami women reported emotional and physical IPV compared to non-Sami women, while there were no ethnic differences in sexual IPV. Women in general reported emotional, physical, and sexual IPV more often than men. Although there may be gender and ethnic differences in the exposure to IPV and CV, the effect that IPV and CV have on mental health seems to be same, regardless of ethnicity and gender.

\section{Abbreviations}

IPV: intimate partner violence

CV: Childhood violence

HSCL: Hopkins symptom checklist

PTS: symptoms of post-traumatic stress

\section{Declarations}

\section{Ethics approval and consent to participate.}

The data collection and storage of data were approved by the Norwegian Data Protection Authority (Datatilsynet). Written informed consent was obtained from all participants. The study was approved by the Regional Committee for Medical and Health Research Ethics (REK-Sør-Øst) and the SAMINOR Project Board.

\section{Consent for publication}

Not applicable.

\section{Availability of data and materials}

Data will be available upon request from the corresponding author.

\section{Competing interest}

The authors declare that they have no competing interest. 


\section{Funding}

The Research Council of Norway provided the funding of this study.

\section{Acknowledgements}

The authors would like to thank all participants who took part in the SAMINOR 2 Questionnaire Survey

\section{References}

1. Mikton CR, Butchart A, Dahlberg LL, Krug EG. Global Status Report on Violence Prevention 2014. Am J Prev Med. 2016;50(5):652-9.

2. Garcia-Moreno C, Jansen HA, Ellsberg M, Heise L, Watts $\mathrm{CH}$. Prevalence of intimate partner violence: findings from the WHO multi-country study on women's health and domestic violence. Lancet. 2006;368(9543):1260-9.

3. Heise L, Ellsberg M, Gottmoeller M. A global overview of gender-based violence. International Journal of Gynecology \&amp; Obstetrics. 2002;78, Supplement 1(0):S5-S14.

4. Krug EG, Mercy JA, Dahlberg LL, Zwi AB. The world report on violence and health. The Lancet. 2002;360(9339):1083-8.

5. Ellsberg M, Jansen $\mathrm{HA}$, Heise $\mathrm{L}$, Watts $\mathrm{CH}$, Garcia-Moreno $\mathrm{C}$. Intimate partner violence and women's physical and mental health in the WHO multi-country study on women's health and domestic violence: an observational study. Lancet. 2008;371(9619):1165-72.

6. Campbell JC. Health consequences of intimate partner violence. Lancet. 2002;359(9314):1331-6.

7. Woods SJ, Hall RJ, Campbell JC, Angott DM. Physical health and posttraumatic stress disorder symptoms in women experiencing intimate partner violence. Journal of midwifery \& women's health. 2008;53(6):538-46.

8. Hovdestad WE, Shields M, Shaw A, Tonmyr L. Childhood maltreatment as a risk factor for cancer: findings from a population-based survey of Canadian adults. BMC Cancer. 2020;20(1):70-11.

9. Golding J. Intimate Partner Violence as a Risk Factor for Mental Disorders: A Meta-Analysis. Journal of Family Violence. 1999;14(2):99-132.

10. Maniglio R. The impact of child sexual abuse on health: A systematic review of reviews. Clin Psychol Rev. 2009;29(7):647-57.

11. Springer KW, Sheridan J, Kuo D, Carnes M. Long-term physical and mental health consequences of childhood physical abuse: results from a large population-based sample of men and women. Child Abuse Negl. 2007;31(5):517.

12. Norman RE, Byambaa M, De R, Butchart A, Scott J, Vos T, et al. The Long-Term Health Consequences of Child Physical Abuse, Emotional Abuse, and Neglect: A Systematic Review and Meta-Analysis (Consequences of Child Nonsexual Maltreatment). 2012;9(11):e1001349. 
13. Brownridge D, Taillieu T, Afifi T, Chan K, Emery C, Lavoie J, et al. Child Maltreatment and Intimate Partner Violence Among Indigenous and Non-Indigenous Canadians. Journal of Family Violence. 2017;32(6):607-19.

14. Widom CS, Czaja S, Dutton MA. Child abuse and neglect and intimate partner violence victimization and perpetration: A prospective investigation. Child Abuse Negl. 2014;38(4):650-63.

15. Barnes JE, Noll JG, Putnam FW, Trickett PK. Sexual and physical revictimization among victims of severe childhood sexual abuse. Child Abuse Negl. 2009;33(7):412-20.

16. Haaland T C, SE \& Schei B. Vold i parforhold- Ulike perspektiver. Oslo: Norsk institutt for by- og regionsforskning; 2005.

17. Neroien Al, Schei B. Partner violence and health: results from the first national study on violence against women in Norway. Scandinavian journal of public health. 2008;36(2):161-8.

18. Thoresen S, Hjemdal OK. Vold og voldtekt i Norge : en nasjonal forekomststudie av vold i et livsløpsperspektiv. Oslo: Nasjonalt kunnskapssenter om vold og traumatisk stress; 2014.

19. Chmielowska M, Fuhr DC. Intimate partner violence and mental ill health among global populations of Indigenous women: a systematic review. Soc Psychiatry Psychiatr Epidemiol. 2017;52(6):689-704.

20. Shannon B. Violent victimization of Aboriginal women in the Canadian provinces, 2009. Juristat. 2011:1D.

21. Burczycka M, S C. Family violence in Canada: A statistical profile, 2016. Statistics Canada; 2018.

22. Daoud N, Smylie J, Urquia M, Allan B, O'Campo P. The Contribution of Socio-economic Position to the Excesses of Violence and Intimate Partner Violence Among Aboriginal Versus Non-Aboriginal Women in Canada. A Publication of The Canadian Public Health Association. 2013;104(4):e278-e83.

23. Kirmayer LJ, Brass G. Addressing global health disparities among Indigenous peoples. The Lancet. 2016;388(10040):105-6.

24. Berglund EL HT, Amdal H \& Heatta K. Den mørke hemmeligheten

https://www.vg.no/nyheter/innenriks/i/3A5gX/den-moerke-hemmeligheten. Verdens Gang (VG). 2016.

25. Berglund H HT, Johansen IC \& Gulbrandsen EA. Ny forskning: samiske kvinner mer utsatt for seksuell vold

https://www.vg.no/nyheter/innenriks/i/mJXB1/ny-forskning-samiske-kvinner-mer-utsatt-for-seksuell-vold. Verdens Gang (VG). 2015.

26. Eriksen AMA, Hansen KL, Javo C, Schei B. Emotional, physical and sexual violence among Sami and non-Sami populations in Norway: The SAMINOR 2 questionnaire study. Scandinavian journal of public health. 2015;43(6):588-96.

27. Eriksen, Hansen, Schei, Sorlie, Stigum, Bjertness, et al. Childhood violence and mental health among indigenous Sami and non-Sami populations in Norway: a SAMINOR 2 questionnaire study. Int $J$ Circumpolar Health. 2018;77(1):1508320. 
28. Brustad M, Hansen KL, Broderstad AR, Hansen S, Melhus M. A population-based study on health and living conditions in areas with mixed Sami and Norwegian settlements - the SAMINOR 2 questionnaire study. Int J Circumpolar Health. 2014;73:23147.

29. Siri S, Eliassen BM, Broderstad AR, Melhus M, Michalsen VL, Jacobsen BK, et al. Coronary heart disease and stroke in the Sami and non-Sami populations in rural Northern and Mid Norway-the SAMINOR Study. Open Heart. 2020;7(1):e001213.

30. Hansen KL, Sørlie T. Ethnic discrimination and psychological distress: a study of Sami and non-Sami populations in Norway. Transcultural psychiatry. 2012;49(1):26-50.

31. Strand BH, Dalgard OS, Tambs K, Rognerud M. Measuring the mental health status of the Norwegian population: a comparison of the instruments SCL-25, SCL-10, SCL-5 and MHI-5 (SF-36). Nordic journal of psychiatry. 2003;57(2):113-8.

32. Lund E, Melhus M, Hansen KL, Nystad T, Broderstad AR, Selmer R, et al. Population based study of health and living conditions in areas with both Sami and Norwegian populations-the SAMINOR study. Int J Circumpolar Health. 2007;66(2):113-28.

33. Garcia-Moreno C PC, Devries K, Stõckl H, Watts C, \& Abrahams N. . Global and regional estimates of violence against women: Prevalence and health effects of intimate parter violence and non-partner sexual violence. Geneva: WHO.; 2013.

34. Tjaden P, Thoennes, N. Prevalence, incidence and consequences of violence against women. Washington: U.S Department of Justice Office of Justice Programs; 2000.

35. Anderson I, Robson B, Connolly M, Al-Yaman F, Bjertness E, King A, et al. Indigenous and tribal peoples' health (The Lancet-Lowitja Institute Global Collaboration): a population study. The Lancet. 2016;388(10040):131-57.

36. Per MCA. Somatic health in the Indigenous Sami population - a systematic review. Int J Circumpolar Health. 2019;78(1):1638195.

37. Campbell DW, Sharps PW, Gary FA, Campbell JC, Lopez LM. Intimate partner violence in African American women. Online J Issues Nurs. 2002;7(1):5.

38. Wangel AM, Schei B, Ryding EL, Ostman M. Mental health status in pregnancy among native and non-native Swedish speaking women: A Bidens study. Acta Obstet Gynecol Scand. 2012.

39. Gilbert R, Widom CS, Browne K, Fergusson D, Webb E, Janson S. Burden and consequences of child maltreatment in high-income countries. Lancet. 2009;373(9657):68-81.

40. Sørlie T, Hansen KL, Friborg O. Do Norwegian Sami and non-indigenous individuals understand questions about mental health similarly? A SAMINOR 2 study. Int J Circumpolar Health. 2018;77(1).

41. Clech-Aas J, Bang Nes R. Psykisk helse i Norge : tilstandsrapport med internasjonale sammenligninger. Oslo: Folkehelseinstituttet; 2011.

42. Hilden M, Schei B, Swahnberg K, Halmesmaki E, Langhoff-Roos J, Offerdal K, et al. A history of sexual abuse and health: a Nordic multicentre study. BJOG. 2004;111(10):1121-7. 
43. Swahnberg IM, Wijma B. The NorVold Abuse Questionnaire (NorAQ): validation of new measures of emotional, physical, and sexual abuse, and abuse in the health care system among women. Eur $\mathrm{J}$ Public Health. 2003;13(4):361-6.

44. Pettersen T. Sámi ethnicity as a variable. Premises and implications for population-based studies on health and living conditions in Norway. UiT The Arctic University of Norway; 2015.

45. Broderstad AR, Hansen S, Melhus M, Broderstad AR. The second clinical survey of the populationbased study on health and living conditions in regions with Sami and Norwegian populations - the SAMINOR 2 Clinical Survey: Performing indigenous health research in a multiethnic landscape. Scandinavian journal of public health. 2019:1403494819845574-.

46. Eliassen B-M, Graff-Iversen S, Melhus M, Løchen M-L, Broderstad AR. Ethnic difference in the prevalence of angina pectoris in Sami and non-Sami populations: the SAMINOR study. Int J Circumpolar Health. 2014;73(1).

47. Jeronimus BF, Riese $H$, Sanderman R, Ormel J. Mutual reinforcement between neuroticism and life experiences: A five-wave, 16-year study to test reciprocal causation. J Pers Soc Psychol. 2014;107(4):751-64.

\section{Supplementary Files}

This is a list of supplementary files associated with this preprint. Click to download.

- IPVandmentalhealthamongSami.pdf 